\title{
Mídias sociais: amplificadores da psicologia humana
}

\author{
Colaboração Aberta ${ }^{1}$ \\ 5 de Outubro de 2020
}

\begin{abstract}
Resumo
Argumentamos que os algoritmos de inteligência artificial das mídias sociais servem como amplificadores de alguns elementos da psicologia humana.
\end{abstract}

palavras-chave: psicologia computacional, redes e mídias sociais, internet, tecnologias digitais

A versão mais atualizada deste artigo está disponível em https://osf.io/pd9ne/download

\section{Como ser coautor(a) deste artigo?}

1. Envie-nos suas observações e responda às seguintes perguntas.

2. Quais discussões você adicionaria a este artigo?

3. Você encontrou algum erro ou argumento inconsistente? Dê uma justificativa detalhada.

${ }^{1}$ Todos os autores com suas afiliações aparecem no final deste artigo. 


\section{Preâmbulo}

4. Dedico este artigo àqueles que acham que estão no controle de suas vidas.

\section{Introdução}

5. Os algoritmos implementados nas redes e mídias sociais estão intimamente relacionados com diversos elementos da psicologia humana, com o claro intuito de reter a atenção de seus usuários.

\section{Os algoritmos das mídias sociais}

6. O âmago das estratégias dos algoritmos das mídias sociais operam com o seguinte conceito:

\section{O semelhante atrai o semelhante.}

7. Eles fazem isso mostrando-lhe conteúdos compativeis com seus interesses, a partir de suas experiências prévias na plataforma.

\section{Definição}

8. $\mathbf{S A S}=o$ Semelhante Atrai o Semelhante

9. SAS remete à estratégia (6) no contexto dos algoritmos implementados nas mídias sociais.

\section{Hipótese}

10. O SAS amplifica e acentua alguns elementos psicológicos do ser humano [1]. 
11. (10) influencia dramaticamente as interações e decisões humanas, conforme discutiremos a seguir.

\section{Problema}

12. Os dados mostram que houve considerável aumento dos níveis de polarização (nos EUA), um aumento da depressão e do suicídio acometendo adolescentes, coincidindo com o ano em que houve aumento significativo da utilização das redes e mídias sociais [2].

13. (12) parece ser uma consequência direta de (10).

14. Em outras palavras, o efeito AMPLIFICADOR das mídias sociais é uma das causas dos problemas psicológicos enfrentados pelas pessoas que nelas se baseiam e que delas se utilizam para compor a visão de seu mundo interno.

\section{Solução}

15. Alterar os algoritmos das redes e mídias sociais no sentido de AMPLIAR e EXPANDIR a CONSCIÊNCIA (AEC) humana [3] por meio da exposição de diferentes perspectivas, colocadas inteligentemente.

16. É importante que (15) seja compreendido e implementado no sentido da COMPLEMENTARIDADE, isto é, mostrar ao sujeito aquilo que lhe falta.

17. A seguir veremos, por meio de exemplos, o que significa ampliação e expansão da consciência humana, no contexto da proposição deste artigo. 


\section{Como funcionaria esse algoritmo?}

18. A seguir apresentamos dois exemplos simples, formativos e reformativos, no sentido da utilização de algoritmos que privilegiem a expansão da consciência.

\section{Um sujeito radical}

19. O sujeito $X$ tem predisposição para opiniões radicais, extremistas.

20. A rede social $Y$ sugere, por exemplo, vídeos (re)formativos para o sujeito $X$, com o intuito de ampliar sua visão de mundo.

21. Com isso, $X$ terá maior poder de discernimento por conhecer mais, reconhecendo outros pontos de vista igualmente positivos.

22. Conhecer e reconhecer mais implica, evidentemente, na expansãa da consciência do sujeito.

23. De um ponto de vista estatístico, em grande escala, (22) trará um bem maior para a qualidade de vida de uma sociedade, promovendo, assim, maior benefício para o gênero humano.

\section{Uma adolescente com bulimia}

24. Uma jovem, com bulimia, em suas pesquisas na internet, encontra vídeos descrevendo hábitos saudáveis de alimentação, bem como palestras motivacionais de psicólogos renomados e especializados no assunto.

\section{Como o google ganha dinheiro?}

25. Vamos elucidar apenas um aspecto da monetização do google de forma bastante simplificada. 
26. O google faz leilão de palavras [4].

27. A empresa que oferecer maior custo por clique aparece em primeiro, na região destinada aos anúncios.

28. Os links que aparecem fora da região de anúncios seguem um outro ecossistema de regras bem delimitadas e extremamente dinâmicas.

29. Um ponto interessante desse tipo de monetização é que, normalmente, é uma estratégia win-win-win, pois o cliente encontra mais facilmente o produto que precisa, a empresa consegue vender mais e o google é recompensado por meio dessa intermediação.

\section{Monetização do algoritmo de expansão da cons- ciência}

30. $\mathbf{A E C}=$ algoritmo de Ampliação e Expansão da Consciência

31. Suponha que o AEC seja implementado nas mídias sociais.

32. Será que a solução proposta em (15) vai continuar gerando lucros para as plataformas digitais e seus respectivos anunciantes?

\section{Uma possível resposta}

33. No fundo, o questionamento (32) pode ser parafraseado assim:

Os algoritmos do tipo $A E C$ continuarão levando seus usuários a um engajamento satisfatório para as empresas envolvidas?

34. A intuição parece dizer que SIM, algoritmos de inteligência artificial que operem no sentido de EXPANDIR nossa consciência, ao invés de amplificar e intensificar uma série de aspectos psicológicos (muitas vezes indesejáveis), continuaria atraindo nossa atenção e gerando lucros para as empresas envolvidas nesse processo de reforma digital. 


\section{Como testar esse modelo?}

35. Produza um algoritmo utilizando inteligência artificial.

36. Simule o algoritmo produzido, em dados armazenados do passado.

37. Convide especialistas para validar a simulação obtida.

\section{O princípio da reciprocidade}

38. Leia sobre o Princípio de Reciprocidade de Ações de Leibniz em [5].

39. Aplicando esse princípio, temos que os algoritmos mudam as pessoas $e$ as pessoas, por sua vez, alteram os algoritmos.

40. (39) deve ser entendido como uma evolução de um processo de $a c ̧ \tilde{a} o$ e reação que ocorre entre as partes envolvidas (sujeito $\rightarrow$ algoritmo $\rightarrow$ sujeito).

41. Não sabemos, no entanto, quando essas alterações serão implementadas, tendo como princípio fundamental e priorizando a ÉTICA e o BEM do gênero humano.

\section{Considerações Finais}

42. Os algoritmos das redes e mídias sociais (até 2020) estão amplificando e intensificando aspectos (muitas vezes negativos) da psicologia humana.

43. A ideia de modificar o algoritmo de modo a expandir a consciência dos sujeitos que utilizam essas plataformas tem o potencial de formar cidadãos emocionalmente mais equilibrados e conscientes do mundo em que vivem, mundo este que se distingue fortemente do mundo virtual. 
44. É evidente que o SAS, aqui proposto, é apenas uma das causas dos problemas das interações humanas causadas pelas plataformas digitais.

45. Outras estratégias devem ser implementadas em conjunto, para conter determinados tipos de comportamentos indevidos, como o bullying digital, por exemplo.

46. Portanto, em resumo, argumentamos que as MÍDIAS SOCIAIS são AMPLIFICADORES da Psicologia Humana.

\section{Ciência Aberta}

O arquivo latex para este artigo, juntamente com outros arquivos suplementares, estão disponíveis [6].

\section{Referências}

[1] Lobo, Matheus P. "Psicologia Quântica: Autoestima E Vaidade." OSF Preprints, 26 Sept. 2020.

https://doi.org/10.31219/osf.io/64ygh

[2] Orlowski, Jeff. Documentário O Dilema das Redes (The Social Dilemma) https://www. thesocialdilemma.com

[3] Lobo, Matheus P. "O Que É Vida?." OSF Preprints, 26 Sept. 2020. https://doi.org/10.31219/osf .io/98bmn

[4] Vise, David A., and Mark Malseed. Google: a história do negócio de mídia e tecnologia de maior sucesso dos nossos tempos. Rocco, 2007.

[5] Lobo, Matheus P. "O Princípio De Reciprocidade De Ações De Leibniz." OSF Preprints, 4 Oct. 2020.

https://doi.org/10.31219/osf .io/qz6vd 
[6] Lobo, Matheus P. "Open Journal of Mathematics and Physics (OJMP)." OSF, 21 Apr. 2020.

https://doi.org/10.17605/osf.io/6hzyp

\section{Colaboração Aberta}

Matheus Pereira Lobo (autor principal, mplobo@uft.edu.br) 1,2 https://orcid.org/0000-0003-4554-1372

${ }^{1}$ Universidade Federal do Tocantins (Brasil)

${ }^{2}$ Universidade Aberta (UAb, Portugal) 